\title{
A ORGANIZAÇÃO E CONFIGURAÇÃO DO ESPORTE UNIVERSITÁRIO NO BRASIL (1940-1980)
}

\author{
Philipe Rocha de Camargo' \\ Fernando Marinho Mezzadri
}

\section{RESUMO}

O objetivo deste estudo foi descrever como se organizou o esporte universitário no país, a partir da Lei no 3.617/41, e quais foram as características dessa organização ao perpassar a ditadura militar no Brasil. Caracterizado como um ensaio exploratório de cunho histórico, utilizamos fontes históricas digitais de acesso livre, bem como a produção acadêmica relacionada ao tema. Foi possível identificar que, no Brasil, o esporte universitário surge no início do século XX como uma manifestação esportiva voltada ao lazer e às relações sociais entre estudantes universitários. Apesar da gênese popular e não institucional, na década de 1940 essa manifestação passa a ser regulamentada pela legislação brasileira, que decide organizar e gerenciar o esporte no país. O Estado passa a se tornar o único financiador e o fiscalizador do desporto estudantil, que num cenário marcado por conflitos político-ideológicos passa a ser regido por um caráter centralizado e formador de atletas.

Palavras-chave: Esporte. Esporte universitário. Legislação

1 Doutorando em Educação Física na Universidade Federal do Paraná (UFPR). Curitiba/Paraná, Brasil. E-mail: philipe_camargo@hotmail.com

2 Doutor em Educação Física. Professor da Universidade Federal do Paraná (UFPR). Curitiba/Paraná Brasil. E-mail: fmezzadri@uol.com.br 


\section{THE ORGANIZATION AND CONFIGURATION OF UNIVERSITY SPORT IN BRAZIL (1940-1980)}

\section{ABSTRACT}

The purpose of this study was to describe how the university sport was organized in Brazil, based on Law $n^{\circ}$. 3.617 / 41, and witch were the characteristics of this organization when crossing the military dictatorship. Characterized as an exploratory historical essay, we used historical digital sources of free access as well as the academic production related to the theme. It was possible to identify that, in Brazil, university sports emerged in the early twentieth century as a sporting manifestation focused on leisure and social relations among university students. In spite of the popular and non-institutional genesis, in the decade of 1940, this manifestation was regulated by the Brazilian Legislation, which decides to organize and manage the sport in the country. The State becomes the sole funder and inspector of student sports, which in a scenario marked by politicalideological conflicts acquires a centralized character for the training of athletes.

Keywords: Sport. University sports. Legislation

\section{LA ORGANIZACIÓN Y CONFIGURACIÓN DEL DEPORTE UNIVERSITARIO EN BRASIL (1940-1980)}

\section{RESUMEN}

El propósito de este estudio fue describir cómo se organizó el deporte universitario en Brasil, con base en la Ley $n^{\circ} .3 .617$ / 41, y cuáles fueron las características de esta organización al cruzar la dictadura militar. Caracterizado como un ensayo histórico exploratorio, utilizamos fuentes digitales históricas de libre acceso así como la producción académica relacionada con el tema. Se pudo identificar que, en Brasil, el deporte universitario surgió a principios del siglo XX como una manifestación deportiva centrada en el ocio y las relaciones sociales entre estudiantes. A pesar de la génesis popular y no institucional, en la década de 1940, esta manifestación fue regulada por la Legislación, que decide organizar y manejar el deporte en el país. El Estado se convierte en el único financiador e inspector de los deportes estudiantiles, que en un escenario marcado por conflictos político-ideológicos adquiere un carácter centralizado para la formación de atletas.

Palabras clave: Deporte. Deporte universitário. Legislación 


\section{INTRODUÇÃO}

Quando nos propomos a analisar a organização e a configuração do esporte universitário no Brasil, sobretudo durante o regime militar, é necessário que retomemos algumas observações acerca dos caminhos históricos percorridos pelo esporte universitário brasileiro. Nesse sentido, nos deparamos com o ano de 1916 como o marco inicial para a realização das competições no Brasil. Nesse ano começaram a ser realizadas as primeiras disputas envolvendo universitários das cidades de São Paulo e Rio de Janeiro.

Inicialmente, os estudantes envolvidos nas competições eram os estudantes do College Mackenzie de São Paulo, os estudantes da Faculdade de Medicina e Cirurgia do Rio de Janeiro e alunos da antiga Escola Politécnica, também do Rio de Janeiro (BORGES; BUONICORE, 2007; STAREPRAVO et al., 2010). É apenas a partir de 1935 que se pode verificar o envolvimento de outros estados nessas competições. Nesse ano, São Paulo e Rio de Janeiro se unem a outros Estados (Bahia, Distrito Federal, Minas Gerais e Paraná) para organizar e estruturar, de maneira autônoma, competições em nível universitário. Até aquele momento tudo acontecia sem apoio ou incentivo do governo.

De acordo com Borges e Buonicore (2007), o esporte universitário nasceu dentro das próprias Instituições de Ensino, utilizando um modelo federativo, organizado e financiado pelas próprias associações esportivas estudantis. Todavia, tal estrutura organizativa não possuía uma composição de gestão oficialmente instituída que representasse o interesse comum de todas as organizações esportivas universitárias envolvidas. Também não havia estrutura financeira estabelecida que possibilitasse o desenvolvimento que aquela organização almejava.

Diante das necessidades financeiras para realização e organização dos Jogos Universitários, os estudantes se viam cada vez mais necessitados de apoio e subsídio financeiros que viabilizassem a continuidade e crescimento do evento esportivo. Borges e Buonicore (2007) relatam que o evento esportivo universitário crescia consideravelmente, chegando a ter o número de participantes dobrado entre uma edição e outra, nos anos de 1940.

O crescimento do esporte universitário se dava não apenas em quantidade de participantes, mas também na qualidade técnica que esses atletas desempenhavam, já que alguns atletas universitários chegaram a se tornar integrantes da delegação brasileira nos principais eventos internacionais e até mesmo medalhistas olímpicos (INCENTIVO, 1984).

O Governo Federal passa a considerar o esporte universitário como dever do Estado, e a partir daquele momento, década de 1940, começaria a subsidiar, fiscalizar e fomentar o esporte estudantil e universitário, na forma da Lei. Contudo, esses interesses possibilitaram, ainda, que o Governo se utilizasse de tal manifestação esportiva como instrumento de reprodução de determinados conceitos e princípios político-ideológicos. Uma atitude concernente a um período permeado por tensões civis e militares que começavam a emergir em alguns países, em especial os que naquele momento se viam em maior evidência política e econômica, os Estados Unidos e a Rússia (PIRES, 1998).

Aquele momento no país, como sublinhado por Starepravo et al. (2010), assinalaria a história do esporte brasileiro não apenas no âmbito universitário, já que a partir de então 
seriam formuladas as primeiras políticas públicas para o esporte no país. Não obstante, naquela mesma ocasião seria estabelecido o início das relações de dependência entre o esporte e Estado; relação presente até hoje na estrutura esportiva do país.

Todas as informações supracitadas nos permitem compreender que o final da década de 1930 e o início da década de 1940 foram fundamentais para a estruturação do esporte universitário como manifestação reconhecida, apoiada e financiada pelo Estado. Por sua vez, este desempenhou não só o papel de financiador, mas o de fiscalizador e controlador das manifestações esportivas no país. As políticas públicas instituídas na década de 1940 (Leis $\mathrm{n}^{\circ} 3.617 / 41$ e 3.199/41) vigoraram por mais de 30 anos e foram essenciais para que se estabelecem as primeiras regulamentações esportivas em âmbito universitário no país. As leis em questão perduraram até meados de 1975 quando novas políticas de regulamentação esportiva foram criadas (Lei Federal n $6.251 / 75$ e o Decreto-Lei ${ }^{\circ}$ 80.228/77), substituindo o texto que tratava do esporte universitário à título de organização, fiscalização e financiamento. Bem como fixando o esporte universitário no subsistema do Esporte Estudantil (BRASIL, 1941a; 1975; 1977).

Entendendo que o principal período da organização esportiva universitária no Brasil se deu a partir da década de 1940 e se estendeu até a década de 1980, esta pesquisa optou por utilizar esse intervalo histórico como recorte temporal, de modo, inclusive, a possibilitar uma análise das peculiaridades que o regime ditatorial introduziu nessa manifestação.

Convém destacar que as produções científico-acadêmicas que tratam do assunto ainda devem ser tratadas como fontes de pesquisas incipientes. Isso se deve ao fato de que nas diversas plataformas de buscas por produções, o assunto esporte universitário, associado a uma trajetória histórica teve pouca produção desenvolvida, limitadas às que foram elaboradas por Starepravo (2006), Dantas Junior (2006; 2009) e Starepravo et al. (2010), que trataram com maior profundidade o histórico dessa manifestação à nível estadual, no Paraná e em Sergipe.

A ausência de pesquisas que abordem a organização do esporte universitário e sua configuração nesse período, que marcou o esporte mundial devido ao caráter espetacularizado e mercantilizado que essa manifestação social aderiu, releva a viabilidade desse estudo. Justifica-se, portanto, a necessidade de compreender como se organizou e configurou o esporte universitário no cenário brasileiro, do início da década de 1940 até o período final do Regime Militar no Brasil (1980).

As informações supracitadas, associadas às produções sobre o tema e às informações que as fontes históricas jornalísticas podem nos proporcionar, nos possibilitarão construir um panorama sobre o esporte universitário no país no período, do qual parte nosso objetivo de estudo: descrever como se organizou o esporte universitário no país (a partir da Lei $n^{\circ} 3.617$, de 1941) e quais foram as características dessa organização ao perpassar o período da ditadura militar no Brasil.

Esse estudo se caracteriza como um ensaio exploratório, de cunho histórico, e foram utilizadas as fontes históricas digitais - jornais da época - disponíveis para acesso livre, que foram encontradas nos sites da Biblioteca Nacional Digital Brasil e do Acervo 
Folha ${ }^{3}$. Nos baseamos, também, na literatura (livros, artigos, dissertações e teses) produzida sobre a organização do esporte universitário brasileiro e que percorreram o período da ditadura militar no país.

\section{A Organização do Esporte Universitário e o início do Regime Militar}

Ao fim da década de 1930, o esporte universitário, organizado pelas próprias Instituições de Ensino por meio de um método associativo entre os cursos universitários, começava a se desenhar como uma organização esportiva de grandes proporções, alcançando diversos estados espalhados pelo território brasileiro. Todavia, essa organização estudantil não possuía uma gestão que representasse oficialmente o interesse de todas as associações universitárias envolvidas nos eventos esportivos, nem o reconhecimento dos órgãos governamentais responsáveis pelo esporte no Brasil.

Até 1939, o Estado não financiava e também não compartilhava as responsabilidades e apoio ao esporte universitário (BORGES; BUONICORE, 2007). Naquele mesmo ano, com a aprovação de um Estatuto próprio, aquela organização estudantil leva ao Governo Federal sua proposta de reconhecimento e oficialização como entidade acadêmica esportiva responsável pelo esporte universitário no país. Naquele momento seria composta a gestão inicial da CUBE, Confederação Universitária Brasileira de Esportes, a instituição responsável pela organização do esporte universitário no Brasil (BORGES; BUONICORE, 2007; STAREPRAVO et al., 2010).

Em entrevista realizada com a pesquisadora Sinei Monteiro, Machado (2010) revela que durante o Governo Vargas, em meados da década de 1930, o esporte universitário, mais expressivamente por meio do futebol, começaria a ganhar visibilidade na sociedade brasileira. Para o autor, o aumento no interesse social pelo esporte gerou, inclusive, interesse midiático e, consequentemente, tornou aquele um momento oportuno para que o esporte passasse a se tornar assunto de mérito dos gestores políticos e obtivessem o apoio estatal. O autor sublinha o crescimento e a utilização do esporte como instrumento publicitário da política. Para ele, isso se justificou pela presença crescente de agentes políticos durante os eventos esportivos que vinham acontecendo desde a primeira década do século XX.

O relato do entrevistado fortalece o discurso das ciências políticas. A narrativa de Sinei destaca e corrobora com diversos autores acerca da importância das pressões populares e dos interesses dos grupos sociais para que um assunto seja discutido em grau de importância e viabilidade pela agenda política (FREY, 2000; SOUZA, 2006), como o que viria a acontecer o esporte universitário no país.

Convém também destacar, como relatado por Pires (1998), aquele momento, décadas de 1930 e 1940, foi um período mundialmente marcado pela utilização do esporte como instrumento de propaganda político-ideológica. Em diversos Estados e Nações a visibilidade e a audiência que o esporte adquiria possibilitou a associação do seu

3 Disponível em: http://hemerotecadigital.bn.br/artigos/correio-da-manh\%C3\%A3 e http://acervo.folha.com.br. 
desenvolvimento técnico e dos resultados alcançados à uma suposta superioridade militar. Isso não foi diferente no Brasil, levando o esporte universitário a passar por um processo de mudanças estruturais, dentre essas mudanças, o financiamento do esporte universitário, que passaria a fazer parte das ações do Estado.

Apesar das primeiras propostas de oficialização e legalização terem iniciado em 1939, foi apenas em 1941 por meio do Decreto presidencial no 3.617 que aquela instituição seria oficializada, recebendo a atual denominação, CBDU - Confederação Brasileira de Desportos Universitários (BRASIL, 1941a). Suas competições passariam a ser denominadas de Jogos Universitários Brasileiros e estariam não mais sobre tutela dos clubes ou das Instituições de Ensino, mas sim, sob fiscalização e instrumentalização do governo federal e do recém-criado, Conselho Nacional de Desportos (CND) e da Lei 3.199, de 14 de abril de 1941 (BRASIL, 1941a; BRASIL, 1941b; STAREPRAVO et al., 2010; BORGES; BUONICORE, 2007).

Tal questão, conforme aponta Mezzadri et al. (2014), mostra que a regulamentação estatal, materializada na legislação, auxiliou na construção da identidade nacional, pois a bandeira do Estado Novo era a de consolidar a base nacionalista, seja no âmbito geral, seja no âmbito esportivo. Nesse caso, o Estado tornou-se bastante presente na vida dos indivíduos, consequentemente atuando sobre o esporte e mais especialmente do esporte universitário, cumprindo o seu papel no processo de fortalecimento da figura estatal e na construção de uma identidade nacionalista e do patriotismo.

A regulamentação do esporte universitário viria acompanhada pela gênese das políticas públicas para o esporte no Brasil, por meio da Lei 3.199/41. Contudo, conforme aponta Starepravo et al. (2010), nesse período a intervenção estatal marcou as ações do Governo, evidenciando, sobretudo, um processo de intervenção jurídica legislativa à política administrativa do esporte brasileiro. De acordo com Mezzadri et al. (2014), tal período acabou por estabelecer uma relação de dependência tutelar entre o esporte e o Estado.

O processo de mudança que se instaurou na estrutura até então conhecida, levou a ampliação do número de estados integrantes da CBDU. Isso possibilitou que outras cidades como Belo Horizonte, Curitiba, Porto Alegre e Recife também organizassem os Jogos Universitários Brasileiros, além do já estabelecido eixo Rio-São Paulo (BORGES; BUONICORE, 2007).

Para que fosse possível a participação dessas outras Instituições no JUBs - Jogos Universitários Brasileiros -, os Centros Acadêmicos dos Cursos passariam a criar as Associações Atléticas Acadêmicas (AAAs), que por sua vez deveriam formar dentro das Universidades uma Federação Atlética Acadêmica, diretamente ligada ao Diretório Acadêmico da instituição (BORGES; BUONICORE, 2007). Após a criação dessas Associações Atléticas, a Universidade poderia pleitear vaga nos jogos, disputando essa vaga com as demais Universidades do estado, já que poderia participar apenas uma Instituição de Ensino por unidade federativa no evento. Nesse caso, a instituição campeã da edição dos Jogos Universitários no Estado iria para o JUBs.

Borges e Buonicore (2007) discorrem sobre o processo de crescimento da competição, que se dava muito rapidamente de uma edição para outra dos jogos. Devido ao 
aumento não apenas no número de universidades participantes, mas também de modalidades disputadas e de Estados envolvidos no evento, os autores revelam que da $3^{\text {a }}$ para a $4^{a}$ edição (São Paulo 1940 e Rio de Janeiro 1942, respectivamente), a competição já havia apresentado um salto de cerca de 500 estudantes participantes, vinculados a 8 estados e ao Distrito Federal. Embora em algumas edições tenha sido observado oscilações nos números de participantes, devido a distância das cidades escolhidas como sede, em 1962 o evento já contava com 12 estados participantes, disputando 06 modalidades, e que somavam cerca de 1500 atletas (BORGES; BUONICORE, 2007).

$\mathrm{O} 2^{\circ}$ Caderno publicado pelo Jornal Correio da Manhã, no dia 23 de dezembro de 1960, retrata o contínuo crescimento no interesse pelo esporte universitário ao longo dos anos que se passaram, e referencia como evidência desse crescimento a iniciativa do Governo Federal e da CBDU em lançar a candidatura do Brasil para ser sede dos Jogos Mundiais Universitários (Universíade) de 1963. Para tanto, o jornal escreve:

Um grande passo para o incremento do esporte no Brasil, e especialmente o esporte universitário; tão desamparado em nosso país. Numa época em que o esporte brasileiro inicia sua fase ascensional, sobressaindo em várias modalidades esportivas, esse empreendimento da CBDU deve ser acolhido com o máximo carinho pelo poder público pelo muito que representará para o nosso esporte (KELLY, 1960, p. 10).

Há de se ressaltar que, embora o esporte universitário apresentasse aspectos de crescimento influenciados, sobretudo pelo apoio do Estado, aquele período, início da década de 1960, não apenas o Brasil, mas toda a América Latina passava por um momento político marcado por conflitos, e o esporte parecia ser utilizado como braço do Estado (BREITKREITZ, 2012). Ao mesmo tempo em que eram visíveis os avanços nos interesses democráticos, o período ficou marcado por algumas manifestações até certo ponto repressivas e pela alternância de governos civis e militares, onde os estudantes eram atores efetivamente envolvidos nesses conflitos. Os fatos e o momento não impediram que a CBDU reivindicasse junto ao Governo algumas ações no que se refere à estrutura esportiva do país.

O $2^{\circ}$ Caderno do Jornal Correio da Manhã, de 01 de julho de 1961, informa que no dia 27 de junho daquele mesmo ano, numa reunião realizada no Palácio do Planalto, o então Presidente Jânio Quadros determina que o Ministério da Educação e Cultura realizasse, em até 20 dias, um levantamento das Universidades que estariam funcionando sem praças esportivas. O presidente solicitou também que fosse dada atenção para que as Universidades criadas a partir daquele momento respondessem ao critério de tê-las (KELLY, 1961a).

Embalados pela primeira reunião, a CBDU segue em seu objetivo de ter a participação efetiva do Governo Federal no subsídio e incentivo ao esporte universitário. Dessa forma, conseguiram do Presidente a liberação de recursos expressivos para que a Delegação Brasileira pudesse participar dos Jogos Mundiais Universitários, em Sofia, Bulgária em 1961 (KELLY, 1961b).

Segundo o redator do caderno esportivo do Jornal Correio da Manhã, Kelly (1961a; 1961c), as notícias a respeito de ações que beneficiavam o esporte universitário brasileiro 
continuariam surgindo, evidenciado, sobretudo pelo apoio que a CBDU estaria recebendo do Presidente da República, que buscava fortalecer o esporte universitário no país. O fato acabou fortalecendo não apenas o esporte universitário em território nacional, mas também a candidatura do Brasil em sediar os Jogos Universitários Mundiais de 1963.

O apoio do Governo Federal à Confederação Brasileira de Desporto Universitário, por meio do Presidente Jânio Quadros continuaria até 1961, quando em 25 de agosto, por uma renúncia até hoje não entendida, o presidente deixa o poder ${ }^{4}$. Assumiria o vice-presidente, João Goulart (ARAUJO; SILVA; SANTOS, 2013). Tais acontecimentos políticos não dissolveria o apoio que a CBDU receberia do Estado, tampouco a simpatia dos órgãos internacionais de organização do esporte. Nesse sentido, embora a candidatura do Brasil como sede das Olimpíadas Universitárias tenha sido cortejada e elaborada durante o Governo Jânio Quadros, a cerca de um ano e sete meses antes da data de abertura do evento, já sob governo de João Goulart, a Federação Internacional de Esportes Universitários (FISU) anuncia a escolha do Brasil como país sede dos Jogos Mundiais Universitários de 1963 (UNIVERSITÁRIOS, 1961; DOMINGOS, 2008; SANTIAGO, 2009).

Marcada por uma transformação forçada pelo autoritarismo político-militar, devido ao golpe de Estado desencadeado em abril de 1964 (MARTINS, 1999), a educação no Brasil, em especial a Educação Física, passa a ter uma premissa de disciplinarização e alto rendimento, oriundos de uma política de desenvolvimento e de eficiência produtiva. Uma política implicitamente apoiada numa perspectiva de padronizar e controlar a ação tanto do professor, quanto do aluno, já que as práticas esportivas seriam reduzidas a algumas poucas modalidades (OLIVEIRA, 2002). Redução essa, que poderia impossibilitar o desenvolvimento e a prática do esporte como um interesse voluntário voltado ao lazer, sendo direcionado a uma manifestação de massificação, mercantilização e espetacularização do esporte.

Naquele período, professores da Escola Nacional de Educação Física, no Rio de Janeiro, denunciaram o abandono do Estado com o esporte universitário, o volume de trabalho e as más condições de desenvolvimento das atividades, que apresentavam aspectos de esquecimento por parte do poder público. As reclamações foram pautadas no pressuposto da necessidade em se incentivar a prática voltada ao desenvolvimento da base esportiva nacional, e que os investimentos deveriam ser direcionados para a adequação das instalações esportivas, reformulação e reorganização do esporte escolar e, consequentemente, do esporte universitário (LAURINDO, 1965).

4 Convém destacar que, embora haja material jornalístico e algumas produções científico-acadêmicas sobre o tema, os motivos que levaram o então presidente, Jânio Quadros, a renunciar não são unânimes. Os autores que abordam o tema apontam que a renúncia foi resultado da soma de diversos fatores. Alguns deles seriam a crença de Jânio Quadros de que havia uma conspiração preparada para derrubá-lo do poder, pressões de organizações sociais, partidos e representantes políticos, tanto em âmbito nacional como internacional. Não obstante a esses motivos, a renúncia, por vezes, foi considerada como uma estratégia de comoção nacional que possibilitasse a legitimação de Jânio Quadros na função presidencial e, consequentemente, o levasse a recondução do cargo com prestígio superior ao que possuía enquanto presidente eleito (CASTELLO BRANCO, 2000; CARVALHO, 2012; SILVA, 2012). 
Naquele novo cenário político do país, a CBDU, entendendo a fragilidade de suas alianças políticas, determinantes para o sucesso dos interesses de um grupo social na esfera política (FREY, 2000; SOUZA, 2006), via-se novamente na necessidade de fortalecer e ampliar os laços com o Governo. A Confederação buscava modos de abarcar maiores incentivos e financiamentos estatais para as competições universitárias em âmbito nacional (BORGES; BUONICORE, 2007).

Contudo, para Starepravo et al. (2010), o apoio e o comprometimento dispensados pelo Estado não estariam associados ao interesse em incentivar a prática esportiva democratizada, pelo lazer e na sua funcionalidade social, mas com o desenvolvimento esportivo em alto nível, com a finalidade de produzir atletas por meio do alto rendimento, levando consequentemente a massificação do esporte. A função de estimular a prática esportiva de caráter social e democrático nas universidades ficou a cargo das Associações Atléticas Acadêmicas (AAAs) e dos Centros Acadêmicos, que já detinham um papel consolidado como entidades promotoras dos eventos esportivos nas suas universidades, e que se posicionavam favoráveis ao crescimento do número de participantes nos jogos, não só pela disputa esportiva, mas pelas relações interpessoais que a vida universitária proporcionava (MELO, 1997).

Em estudo feito por Melo (1997), o autor reforça que a vida política do país não pautava como assunto de interesse das Associações Atléticas Acadêmicas (AAAs), que se propunham a discutir e se envolver apenas com os assuntos que se referiam à prática esportiva, situação oposta ao que acontecia nos Centros Acadêmicos. Para o autor, esse fato pôde ser mais fortemente confirmado durante o Golpe Militar, quando os Centros Acadêmicos foram fechados, mas Associações Atléticas não.

O tratamento diferenciado dispensado as Associações Atléticas teria sido fundamentado em duas razões. A primeira delas foi a necessidade de manter o incentivo ao desenvolvimento do potencial físico e esportivo dos estudantes, como estratégia fundamental para o aperfeiçoamento do esporte nacional e sua utilização como instrumento de propaganda político-ideológica. A segunda razão foi a possibilidade de utilizar a atividade esportiva com o objetivo de ocupação e, consequentemente, desviar a atenção dos estudantes da vida política do país, já que o Estado parecia não estar interessado em permitir que os estudantes se manifestassem abertamente contra o regime imposto naquele momento (BATISTA; GONÇALVES JUNIOR, 2010).

Nesse contexto, o esporte desenvolvido tanto no âmbito escolar, quanto universitário, firmado num propósito formador de atletas de alto rendimento, não foi relacionado a princípios educativos ou sociais, mas focados em resultados e busca por medalhas. À exemplo disso, nas escolas, as aulas de educação física inclinavam-se a ser tratadas como momentos de treinamento e seleção de futuros atletas que poderiam se tornar "armas" do esporte nacional (MONTEIRO, 2009).

O Governo brasileiro, assim como em outros países, especialmente os governos norte-americano e russo estavam se utilizando do esporte como estratégia de fabricação de atletas e, talvez, campeões. Esse modelo lhes imputaria um posto favorável no que se refere não só a visibilidade no cenário político-ideológico mundial, mas também no que refletiria na capacidade de treinamento esportivo baseado em técnicas militares (PIRES, 1998). 


\section{A configuração do esporte estudantil e seu percurso rumo ao fim do regime militar}

Embora algumas instituições esportivas responsáveis cobrassem um maior direcionamento de recursos financeiros ao esporte universitário (CRONISTAS, 1968), para alguns autores, os incentivos e os subsídios que o Governo direcionava aos eventos esportivos estudantis e universitários não foram interrompidos, e aconteciam gradativamente segundo as necessidades e, acima de tudo, como previa a legislação do esporte no país (CASTELLANI FILHO, 2003; BATISTA; GONÇALVES JUNIOR, 2010). Oliveira (2004) destaca que esse aumento não foi associado à elaboração ou execução de políticas para o esporte universitário, mas se caracterizou como um método utilizado para desmobilizar a resistência crescente dos estudantes ao regime, associado a uma estratégia de ocupação do tempo, por meio de atividades esportivas, e assim evitar qualquer tipo de manifestação contrária ao regime.

Batista e Gonçalves Junior (2010), e Jaco (2012) associaram o aumento nos investimentos e no incentivo ao esporte a estratégias de massificação de algumas modalidades esportivas. Os autores ressaltam que, no âmbito esportivo escolar, um novo decreto de lei (Decreto 69450/71) viria interferir no modo como o esporte era organizado nas escolas. Os alunos seriam separados por sexo e as turmas deveriam ser compostas por aqueles que apresentassem condições físicas semelhantes (BRASIL, 1971).

De acordo com esses autores, a percepção obtida daquele modelo de divisão de turmas, era a de que esse novo método possibilitaria ao professor dar maior atenção aos alunos que possuíssem melhor habilidade e destreza nas modalidades esportivas. O esporte estudantil passa a adquirir, na forma da lei, um desenho piramidal de desenvolvimento técnico esportivo - da formação de atletas ao alto rendimento -, já que, a partir dessa estratégia alguns alunos poderiam se tornar ótimos atletas e compor a elite do esporte brasileiro. A nova política educacional institucionalizada passa a proteger, legalmente, um comportamento já observado desde os primeiros momentos da instituição do regime militar, a massificação e a segregação do esporte no âmbito escolar.

Nesse sentido, Souza (2006) argumenta que em países em desenvolvimento ou marcados por fragilidades democráticas - como era o caso do Brasil diante do cenário ditatorial -, a formulação de políticas públicas é caracterizada pela incapacidade de promover a equidade de direitos, bem como a inclusão social. Aplica-se, portanto, a situação antidemocrática na qual o esporte foi inserido, evidenciado pela promulgação de políticas restritivas e focalizadas.

Os reflexos dessa nova 'política educacional' se estenderiam ao desporto universitário. A partir dos resultados esportivos, os estudantes que se destacassem nas suas modalidades e, consequentemente, nas competições escolares teriam prioridade na concessão de bolsas de estudo para ingressarem em uma Universidade (BATISTA; GONÇALVES JUNIOR 2010). Por esse motivo, a quantidade de Instituições de Ensino Superior no país aumentava, desencadeando o aumento no número de estudantes participantes das edições dos jogos estudantis e universitários. O Estado manteve o seu papel estimulando esse crescimento, reproduzindo a premissa de escola responsável pela especialização esportiva (JACO, 2012). 
Para os estudiosos das ciências do esporte que contextualizaram o desporto durante o período militar no Brasil (PIRES, 1998; DANTAS JUNIOR, 2008; TEIXEIRA, 2009; BATISTA; GONÇALVES JUNIOR, 2010), o esporte passa a ser permeado por medidas que objetivavam sua massificação, sobretudo no contexto escolar. É possível argumentar que essas políticas educacionais adotadas pelo governo, se configuraram de forma a incentivar o crescimento do número de praticantes das modalidades e incrementar o grupo de atletas de alto nível no país.

Ao criticar o modelo esportivo imposto pelo regime, Castellani Filho (2003) ressalta que as políticas de Governo ali estabelecidas reforçavam o interesse em desenvolver atletas de alto nível. Consequentemente, isso possibilitaria a conquista de resultados favoráveis nas competições esportivas. Não obstante, a partir da empatia com o esporte e a promoção de um sentimento nacionalista, seria possível utilizar desses resultados para sublinhar a provável relação entre a ascensão do esporte e o desenvolvimento do país.

Embora essas políticas educacionais direcionadas ao esporte tenham tornado as práticas esportivas, no âmbito escolar, vinculadas ao esporte de alto rendimento, os esportes universitário e olímpico pareciam não ter sentido os efeitos dessa imposição, de modo que o Jornal Correio da Manhã (UMA CARTA, 1966) inicia uma campanha de críticas à organização do esporte do Brasil. Tais críticas eram justificadas pelos resultados indesejados conquistados pelo país nas últimas edições dos Jogos Universitários Mundiais (1965), bem como os resultados das seleções olímpicas nas edições esportivas internacionais que se davam. Todavia, o Jornal seguia defendendo o empenho e a representação dos atletas brasileiros, lançando culpa às autoridades como sendo os reais responsáveis pelo descaso com o esporte universitário, alegando desrespeito e falta de cumprimento às leis.

Em meio às críticas sobre a falta de desenvolvimento de ações, e em meio a protestos contra o regime, os eventos esportivos universitários continuavam acontecendo de maneira autônoma pelo país. Tal como os Jogos da Primavera, que foram realizados no período entre 1964 e 1985 em Sergipe, organizados pela Federação das Atléticas dos Estudantes de Sergipe (FAES). O evento ficou marcado pela participação de agentes do corpo político que praticavam uma tentativa de reproduzir os interesses do Governo vigente (DANTAS JUNIOR, 2009).

Dantas Junior (2006) ressalta que outros eventos esportivos universitários começavam a ficar marcados por tensões decorrentes do período militar. Mesmo que aqueles eventos não apresentassem características diretas de contestações ao regime político, naquele período os eventos esportivos eram constantemente permeados pela presença de sujeitos ligados à vida política do país, que buscavam assegurar e reafirmar a importância do atual regime à ordem e ao desenvolvimento da nação. Contudo, em contraposição, havia outros atores do meio político, midiático e, principalmente, universitário que procuravam, sem o rigor da confrontação, estabelecer ideias e posições opostas ao regime.

O crescimento do interesse político pelas manifestações esportivas era justificado por dois fatores associados: I) o processo de ideologização do esporte e seu uso como instrumento de propaganda político-ideológica. Até aquele momento fortemente utilizado pelo regime militar como forma de "desviar a atenção do povo brasileiro das atrocidades 
da ditadura militar e forjar uma coesão nacional" (PIRES, 1998, p. 30); e II) o início de um processo de mercadorização do esporte, marcado pelo ingresso de grandes conglomerados industriais no âmbito esportivo, associado por uma filosofia agressiva de marketing e divulgação de produtos ligados ao esporte. O que gerou a massificação esportiva nos meios de comunicação e motivou a gênese de uma cultura direcionada ao consumo do esporte e seus produtos (PIRES, 1998).

Esse período, permeado pelas expectativas em torno da Copa de 1970, em que a mobilização de instituições estudantis e dos próprios estudantes em favor do esporte universitário aumentava, a imprensa brasileira se viu fortemente criticada por não darem cobertura efetiva às manifestações universitárias. Elas se viam desfavorecidas pelos instrumentos midiáticos, mesmo diante do atual fortalecimento do desporto universitário no cenário esportivo e político nacional (CRONISTAS, 1968).

Por meio da utilização do esporte como instrumento ideológico, o Estado mantinha-se cada vez mais presente na vida dos indivíduos e, sob a presidência do General Ernesto Geisel, na década de 1970 foi criada e implementada uma nova política envolvendo as práticas esportivas. Nesse período, foram promulgadas a Lei Federal $\mathrm{n}^{\circ} 6.251 / 75 \mathrm{e}$ o Decreto-Lei no 80.228/77, que instituíram a Política Nacional de Desenvolvimento da Educação Física e Desporto. A partir dessa regulamentação "criou-se o Sistema Nacional de Esportes, onde o esporte universitário foi incluído no subsistema do esporte estudantil" (STAREPRAVO, 2006, p. 52). A nova Política para o esporte estabeleceu fontes de recursos específicos para essas manifestações e determinou ao Estado a prioridade no apoio ao esporte estudantil (BRASIL, 1975).

A legislação supracitada caracterizou um avanço nas políticas esportivas do país, devido ao estabelecimento de fontes de recursos financeiros específicos ao esporte, bem como pela conceituação inédita das formas de organização do esporte no país. Contudo, demonstrou aspectos de contradição acerca dos papéis do Estado frente às manifestações esportivas, já que a nova legislação apesar de garantir o direito e a liberdade de organização do esporte a iniciativa privada, imputou, contraditoriamente, como dever do Estado a função de distribuir recursos financeiros, dar suporte legal e fornecer auxílio técnico para as práticas esportivas. Para Starepravo (2011), a contradição e falta de clareza como é tratada a Lei Federal $n^{\circ} 6.251 / 75$, na verdade é característica da reafirmação acerca da centralização e da posição do poder público como o grande controlador das estruturas esportivas no país.

De acordo com os conceitos da ciência política de Laswell (1984) e reafirmadas por Souza (2006), as políticas públicas implementadas são reflexos de decisões tomadas acerca do que fazer ou não fazer, e as análises dessas ações podem fornecer respostas para questões como: quem ganha o quê, por que e que diferença faz. A exemplo disso, da aplicação da nova legislação esportiva, a Lei Federal no 6.251/75, Starepravo e Mezzadri (2006) destacam que a implementação do Sistema Nacional de Esportes, foi fundamental para a realização dos Jogos Universitários no estado do Paraná a partir da década de 1980. Justificado por essas normas, que regulamentavam o subsídio financeiro para a realização dos Jogos Universitários e Estudantis no país e da prerrogativa de que o Estado se tornava 
o principal financiador do desporto estudantil brasileiro, a Federação Paranaense de Desporto Universitário passou a formalizar as solicitações de recursos financeiros ao Governo Federal para a realização dos eventos esportivos universitários no estado.

A partir desse período, início da década de 1980, e junto com essas novas regulamentações esportivas, inicia-se um processo de redemocratização e abertura política no país. Esse processo fez surgir novas relações na sociedade brasileira, e possibilitou uma maior autonomia dos indivíduos frente ao controle do Estado (STAREPRAVO, 2006; ARAÚJO, SILVA e SANTOS, 2013). Dada a essa reabertura política e ao processo de redemocratização, os movimentos esportivos e estudantis, em especial a UNE - União Nacional dos Estudantes - recobraram um posicionamento efetivo do Governo e da CBDU, quanto ao fim da estrutura esportiva que mantinha seu caráter autoritário, de massificação e centralizador das ações esportivas (REBELO, 1981; STAREPRAVO; MEZZADRI, 2006; STAREPRAVO et al., 2010).

As cobranças realizadas pela UNE se refletiram aos meios de comunicação, devido ao fato de que na Olimpíada de Los Angeles de 1984, vários dos medalhistas brasileiros [do vôlei, judô, atletismo e natação] eram, na verdade, atletas universitários e, ainda assim, a mídia e tão pouco o Governo destacavam a importância do esporte universitário. A matéria do jornal Folha de São Paulo (INCENTIVO, 1984) corroborava com as posições tomadas pela União Nacional dos Estudantes, ao expor que, apesar de ser considerado e tratado como esporte amador, o esporte universitário sempre foi responsável por formar vários dos principais atletas brasileiros. Isso posto, era necessário que o esporte universitário fosse estimulado e recebesse recursos suficientes para que, de fato, pudesse proporcionar o beneficiamento do esporte brasileiro.

\section{CONSIDERAÇÕES FINAIS}

A partir das informações levantadas, esse estudo concluiu que, inicialmente, o esporte universitário brasileiro surgiu e se consolidou como uma manifestação democrática, voltada ao lazer e a prática social. Isso se deu por intermédio e interesse dos próprios estudantes, que se engajaram e se mobilizaram com o objetivo de criar uma organização que gerenciasse e instituísse o esporte universitário no país. Para isso, necessitavam não apenas do apoio do Governo Federal quanto à sua oficialização, como também de apoio financeiro para a realização dos eventos, ao passo que as competições ganhavam a aderência nacional. Contudo, ao ser inserido no contexto legislativo da organização esportiva no país, por meio das Leis 3.199/41 e 3.617/41, o esporte universitário teve sua configuração inserida num sistema esportivo de caráter centralizador, de responsabilidade e fiscalização exclusiva do Estado.

A inserção do esporte universitário na legislação nacional, aliada ao momento político do país e do mundo, refletiu não apenas na centralização e controle do esporte nas mãos do estado, como também possibilitou que ele fosse utilizado como instrumento de reprodução e propaganda político-ideológica, pertinentes à época. Não obstante, foi pautado numa perspectiva de alto rendimento e de produção de atletas. Uma perspectiva 
iniciada, inclusive, nas aulas de educação física escolar, que também se tornaram reflexo dos parâmetros esportivos assumidos naquele momento.

O esporte universitário apresentou aspectos evidentes de crescimento, tanto no que se refere a aderência à prática esportiva nas universidades, quanto à visibilidade que essa manifestação obteve. Dentre outras coisas, isso se deve ao fato de que, por diversas vezes, as delegações olímpicas brasileiras tiveram o suporte de atletas provenientes dessas competições universitárias, e que alguns desses se tornaram medalhistas olímpicos. Todavia, o esporte universitário continuou sendo pouco beneficiado por investimentos públicos, ainda que essa deveria ser uma prioridade do Estado, garantido pela legislação.

Convém ainda destacar que, apesar do aumento no número de participantes e das conquistas olímpicas obtidas por esses atletas universitários, os veículos midiáticos continuavam a se mostrar não interessados por essa manifestação esportiva. Esses veículos não acompanharam a ascensão do esporte universitário e seus medalhistas, enquanto voltavam toda a atenção aos eventos esportivos internacionais, que refletiam as disputas político-ideológicas das principais potências mundiais, e começavam a demonstrar os primeiros sinais de espetacularização do esporte.

\section{REFERÊNCIAS}

ARAUJO, Maria Paula; SILVA, Izabel Pimentel da; SANTOS, Desirree dos Reis (Org.). Ditadura militar e democracia no Brasil: história, imagem e testemunho, $1^{\text {a }} \mathrm{Ed}$, Rio de Janeiro: Ponteio, 2013.

BATISTA, Gustavo; GONÇALVES JUNIOR, Luiz. A Educação Física Escolar no Período da Ditadura Militar: Análise de Depoimentos de ex-alunos da Cidade de Brotas/SP. In: Seminário de Estudos em Educação Física Escolar, 3º , 2010, São Carlos. Anais. São Carlos: CEEFE/UFSCar, 2010.

BORGES, Elisa de Campo; BUONICORE, Augusto César. Memória do Esporte Educacional Brasileiro: Breve história dos Jogos Universitários e Escolares. São Paulo, Centro de Estudos e Memória da Juventude, 2007.

BRASIL. Decreto-Lei 3.199, 14 de Abril de 1941. Estabelece as bases de organização dos desportos em todo o país. Disponível em: < http://www.planalto.gov.br/ccivil_03/ decreto-lei/1937-1946/Del3199.htm >. Acesso em: 13 mar. 2016. 1941a.

. Decreto-Lei 3.617, 15 de Setembro de 1941. Estabelece as bases de organização dos desportos universitários. Disponível em: < http://presrepublica.jusbrasil.com.br/ legislacao/126690/decreto-lei-3617-41? ref =home > . Acesso em: 13 mar. 2016. 1941b.

BRASIL. Decreto no 69.450, de $\mathbf{1}^{\circ}$ de Novembro de 1971. Disponível em: < http://www. planalto.gov.br/ccivil_03/decreto/d69450.htm > . Acesso em: 13 mar. 2016.

. Decreto $\mathbf{n}^{\circ}$ 80.228, de 25 de Agosto de 1977. Disponível em: < http://www2. camara.leg.br/legin/fed/decret/1970-1979/decreto-80228-25-agosto-1977-429375publicacaooriginal-1-pe.html>. Acesso em: 13 mar. 2016. 
BRASIL. Lei $\mathbf{n}^{\mathbf{0}}$ 6.251, de 08 de Outubro de 1975. Disponível em: < http://www2.camara. leg.br/legin/fed/lei/1970-1979/lei-6251-8-outubro-1975-357712-veto-36896-pl.html > . Acesso em: 13 mar. 2016.

BREITKREITZ, Luciano Anderson. A ditadura e o futebol na América do Sul: a construção de um imaginário coletivo através das copas do mundo de 1970 e 1978. Revista Semina, v. 11 n. 01, 2012.

CASTELLANI FILHO, Lino. Educação Física no Brasil: a história que não se conta. Campinas, Papirus, 2003.

CARVALHO, Tamiris. A renúncia de Jânio Quadros nas páginas dos jornais Última Hora (Porto Alegre) e A Razão (Santa Maria). In: XI Encontro Estadual de História, 23-27 jul. 2012. Rio Grande, Anais... Rio Grande do Sul: Universidade Federal do Rio Grande (FURG), 2012.

CASTELLO BRANCO, Carlos. A renúncia de Jânio: um depoimento / Carlos Castello Branco. Brasília: Senado Federal, Conselho Editorial, 2000.

CRONISTAS e técnicos abrem o I seminário. Folha de São Paulo, São Paulo, 19 de mar., 1968. Caderno 2, p 6.

DANTAS JUNIOR, Hamilcar Silveira. Jogos da Primavera do Estado de Sergipe: A Iniciação da Esportivização Espetacularizada (1964-1967). In: Seminário Nacional de Estudos e Pesquisas: História, Sociedade e Educação no Brasil, 7º, Unicamp, 2006. Anais... Campinas: Histedbr, 2006.

DANTAS JUNIOR, Hamilcar Silveira. A "esportivização" da Escola na Sociedade do Espetáculo: o caso dos Jogos da Primavera em Sergipe (1964-1995). Revista HISTEDBR, Campinas, n.35, p. 108-125, set. 2009.

DANTAS JUNIOR, Hamilcar Silveira. A Esportivização da Educação Física no Século do Espetáculo: Reflexões Historiográficas. Revista HISTEDBR, Campinas, n.29, p.215232, mar. 2008.

DOMINGOS, Charles Sidarta Machado. Os Jogos Mundiais Universitários de Porto Alegre (30/08 a 08/09 de 1963). Monographia, Porto Alegre, n. 03, p. 147-172, 2008.

FREY. Klaus. Políticas públicas: Um Debate Conceitual E Reflexões Referentes À Prática Da Análise De Políticas Públicas No Brasil. Planejamento e Políticas Públicas, n 21, 2000. INCENTIVO é fundamental para desenvolver o esporte. Folha de São Paulo, São Paulo, 17 set., 1984. p. 17.

JACO, Juliana Fagundes. Educação Física Escolar e Gênero: Diferentes maneiras de participar das aulas. Dissertação (Mestrado) - Faculdade de Educação Física, Universidade Estadual de Campinas, Campinas, 2012.

KELLY, Sylvio. Esporte Universitário. Jornal Correio da Manhã, Rio de Janeiro, 23 dez. 1960. $2^{\circ}$ Caderno, p 10.

KELLY, Sylvio. Quatro Bordas: O Presidente e o Esporte Universitário. Jornal Correio da Manhã, Rio de Janeiro, 01 jul. 1961. $2^{\circ}$ Caderno, p 5. 1961 a. . N 02. Rio de Janeiro, 02 jul 1961. $2^{\circ}$ Caderno, p 6. $1961 \mathrm{~b}$. 
maio/2018

. N 03. Rio de Janeiro, 07 jul 1961. $2^{\circ}$ Caderno. 1961c.

LASWELL, Harold Dwight. Política: Quem Ganha o que, Quando, Como. Brasília, Ed. Universidade de Brasília, 1984.

LAURINDO, Ulisses. Pista e Campo: Reformulação do Esporte tem Apoio de Professor. Jornal Correio da Manhã, Rio de Janeiro, 24 jan. 1965. $2^{\circ}$ Caderno, p 22.

MACHADO, Diolene. Esporte a serviço da Ditadura. Jornal Beira do Rio. UFPA, 2010.

MARTINS, Ricardo Constante. Ditadura Militar e Propaganda Política: A Revista Manchete

Durante o Governo Médici. Dissertação (Mestrado) - Centro de Educação e Ciências Humanas, Universidade Federal de São Carlos, São Carlos, 1999.

MELO, Victor Andrade de. O Movimento Estudantil na Educação Física Brasileira: Construção, Atuação e Contribuições na Escola Nacional de Educação Física e Desportos. Movimento, ano 4, n 7, 1997

MEZZADRI, Fernando Marinho. et al. Sport Policies in Brazil. International Journal of Sport Policy and Politics, [S.I.], p. 1-12, 2014.

MONTEIRO, Sinei Soares. Futebol, Ditadura e Trabalho: uma análise das relações políticas e sociais no campo desportivo paraense (1964-1978). Dissertação (Mestrado) - Instituto de Filosofia e Ciências Humanas, Universidade Federal do Pará, Belém, 2009.

OLIVEIRA, Marcus Aurelio Taborda de. Educação Física Escolar e Ditadura Militar no

Brasil (1968-1984): Historia e Historiografia. Educação e Pesquisa, São Paulo, v. 28, n. 1, p. 51-75, jun. 2002.

OLIVEIRA, Marcus Aurelio Taborda de. Educação Física Escolar e Ditadura Militar no Brasil (1968-1984): Entre a Adesão e a Resistência. Rev. Bras. Cienc. Esporte, Campinas, v. 25 , n. 2, p. 9-20, jan. 2004

PIRES, Giovani de Lorenzo. Breve Introdução ao Estudo dos Processos de Apropriação Social do Fenômeno Esporte. Revista da Educação Física/UEM, Maringá, ano 9, num 1, p. 25-34, 1998.

REBELO, Aldo. 1981: A UNE e o avestruz. Folha de São Paulo, São Paulo, 31 dez. 1981. Cad. Opinião, p 3.

SANTIAGO, Diná Pettenuzzo. Jogos Mundiais Universitários de 1963: Repercussões no Associativismo Esportivo da Cidade de Porto Alegre/RS. Dissertação (Mestrado), Escola de Educação Física, Universidade Federal do Rio Grande do Sul, Porto Alegre, 2009.

SILVA, Ionio Alves da. A renúncia de Jânio e o movimento pela posse de Goulart: um encontro de Castello e Lucídio. Alceu, v. 13, n.25, p. 37-49, jul./dez. 2012.

SOUZA, Celina. Políticas Públicas: Uma Revisão da Literatura. Sociologias, Porto Alegre, ano 8, n 16, 2006.

STAREPRAVO, Fernando Augusto. O Esporte Universitário Paranaense e suas Relações com o Poder Público. Dissertação (Mestrado), Setor de Ciências Biológicas, Universidade Federal do Paraná, Curitiba, 2006.

STAREPRAVO, Fernando Augusto. MEZZADRI, Fernando Marinho. Reflexões sobre o Esporte Universitário Paranaense no Ano de 1983. In: $10^{\circ}$ Congresso Brasileiro de História do Esporte, Lazer, Educação Física e Dança, 2006, Curitiba. Anais. Curitiba, DEF - UFPR. 2006. 
STAREPRAVO, Fernando Augusto. et al. Esporte Universitário Brasileiro: Uma Leitura a partir de suas Relações com o Estado. Rev. Bras. Cienc. Esporte, Campinas, v. 31, n. 3, p. 131-148, maio 2010.

STAREPRAVO, Fernando Augusto. Políticas Públicas de Esporte e Lazer no Brasil: aproximações, intersecções, rupturas e distanciamentos entre os Subcampos Político/Burocrático e Científico/Acadêmico. Tese (Doutorado em Educação Física), Universidade Federal do Paraná, 2011.

UMA CARTA. Jornal Correio da Manhã, Rio de Janeiro, 18 dez., 1966. Caderno 2, p 3.

UNIVERSITÁRIOS. Jornal Correio da Manhã, Rio de Janeiro, 07 set., 1961. Caderno 2, p 6.

Recebido em: Fevereiro/2017 Aprovado em: Maio/2017 